\title{
EDITORIAL
}

\section{Help us find the cures}

\author{
Delyth Morgan \\ See related research by Eccles et al., http://breast-cancer-research.com/content/15/5/R92
}

\begin{abstract}
Despite significant advances in research, breast cancer is still the most common form of cancer, with 50,000 cases diagnosed and 12,000 dying of the disease each year in the UK. In October 2013, Breast Cancer Campaign published a Gap Analysis of breast cancer research that provides us with what we need to know about and what we now need to do to overcome - prevent, cure and outlive - breast cancer. In addition to highlighting the gaps in our understanding of breast cancer, the paper identifies five strategic solutions, which require a collaborative approach amongst researchers in academia and industry, funders, donors, policy-makers and parliamentarians, healthcare professionals and patients to achieve significant progress. Breast Cancer Campaign is calling for funding organizations to reverse the decline in resources targeted towards breast cancer research, an improved and collaborative infrastructure to support breast cancer research, multidisciplinary collaboration and improved clinical trial design. We hope that breast cancer can be overcome by 2050, but this can only be achieved through collaboration with others. The actions that will make a difference have been identified and we must act now.
\end{abstract}

\section{Help us find the cures}

Despite significant advances in research, breast cancer is still the most common form of cancer, with 50,000 cases diagnosed and 12,000 dying of the disease each year in the UK. The goal of Breast Cancer Campaign is to change this.

\section{Identifying the gaps}

In 2008, Breast Cancer Campaign published its first Gap Analysis paper, which identified the gaps that existed in breast cancer research that, if addressed, would accelerate research progress [1]. A key issue highlighted by the

Correspondence: ChiefExec@breastcancercampaign.org

Breast Cancer Campaign, Clifton Centre, 110 Clifton Street, London EC2A $4 \mathrm{HT}$, UK
56 authors was the lack of access to high-quality clinical material, leading Breast Cancer Campaign to establish the UK's first ever national breast cancer tissue bank, a unique collaboration with four leading institutions [2].

Five years on, Breast Cancer Campaign has published their second Gap Analysis, which provides a detailed assessment of what we need to know about and what we now need to do to overcome - prevent, cure and outlive breast cancer [3]. Involving over 100 internationally recognized scientists, clinicians, healthcare experts and patients, we believe it to be the most comprehensive analysis of breast cancer research ever to have taken place.

The top 10 gaps have been identified and prioritised in key areas, such as genetics, prevention, diagnosis, treatment and support. We are heading towards a future where breast cancer can be overcome and outlived. But to reach vital milestones, as a community we must address these critical gaps now.

\section{Time to act}

In addition to highlighting the gaps in our understanding of breast cancer, the paper identifies five strategic solutions, which require a collaborative approach amongst researchers in academia and industry, funders, donors, policy-makers and parliamentarians, healthcare professionals and patients to achieve significant progress.

To accompany the Gap Analysis paper, Breast Cancer Campaign has published 'Help us find the cures: An action plan to tackle critical gaps in breast cancer research, which sets out the charity's ambitions for the future and pinpoints 66 specific actions that will be crucial in filling the gaps [4]. The paper calls for funding organizations to reverse the decline in resources targeted towards breast cancer research, an improved and collaborative infrastructure to support breast cancer research, multidisciplinary collaboration and improved clinical trial design.

A key priority for accelerating progress is the routine collection and use of sequential human breast cancer tissue and blood samples, both during cancer development and treatment as well as from local and distant recurrences. In response to recent evidence showing that a 
biopsy of recurrent and metastatic breast cancers can change the way one in six women are treated, we are calling on the National Institute for Health and Care Excellence to review their advanced breast cancer guideline. Over the next 5 years we will also invest in a significant expansion of the Breast Cancer Campaign Tissue Bank, addressing existing gaps in tissue, data, biomarkers and models to become one of the world's leading banks for breast cancer-related research materials. We will expand our collection of metastatic cancer samples and begin to collect sequential tissue samples, enabling scientists to study treatment response, resistance, indicators of relapse and progression from primary to metastatic cancers. To accelerate progress in risk, prevention and imaging research, we will also introduce the routine collection of breast density data and mammographic imaging alongside samples, as well as developing a mechanism to collect normal breast tissue. However, implementing these changes will require the cooperative efforts of our community collaboration will be critical to create a central, wellorganized and utilized biobanking resource for breast cancer research.

The charity aims to raise more than $£ 100$ million over the next decade to specifically target the critical gaps in breast cancer research, increasing previous investment in every area of our work. We are aiming to increase our investment in research in upcoming grant rounds and are currently seeking high-quality research proposals to tackle the gaps. Expanding beyond our grant funding schemes, we have also created the new Collaborators for a Cure Fund dedicated to addressing the critical research gaps, and we are keen to hear from anyone wanting to discuss new collaborations and initiatives.

Breast Cancer Campaign hopes that breast cancer can be overcome - prevented, cured and outlived - by 2050, but this can only be achieved through collaboration with others. The government, academics, clinicians, healthcare professionals, charities, funding bodies and all those that care about breast cancer need to work together to plug the gaps.

The actions needed to make the difference have been identified and we must act now. Please visit the website for details on how to apply for research funding or tissue samples, and for information on collaborating with Breast Cancer Campaign to address the gaps [4].

\section{Competing interests}

DM is Chief Executive of Breast Cancer Campaign, which facilitated the 2008 and 2013 Gap Analysis projects, and has since produced an action plan to tackle the gaps in breast cancer research. She is also a member of the House of Lords, and sits on the Board of the National Cancer Research Institute. July 2004 to present, House of Lords, now a cross-bencher; 2008 to 2010, Children's Minister, Minister for Intellectual Property, and government spokesperson in the Lords; 2010, Opposition Spokesperson for Education. Honorary charity positions: patron of the Sheila McKechnie Foundation, patron of Pancreatic Cancer UK, Honorary President of Cancer 52, and Trustee of Lung Cancer Campaign Carmarthenshire. DM is a science graduate and Fellow of University College London. She is also an Honorary Fellow of Cardiff University and the Institute of Cancer Research, and a member of the Royal Marsden NHS Hospital Trust. She is a Founding Fellow of Breakthrough Breast Cancer.

Published: 30 Oct 2013

\section{References}

1. Thompson A, Brennan K, Cox A, Gee J, Harcourt D, Harris A, Harvie M, Holen I, Howell A, Nicholson R, Steel M, Streuli C: Evaluation of the current knowledge limitations in breast cancer research: a gap analysis. Breast Cancer Res 2008, 10:R26.

2. Speirs V, Morgan A: Breast cancer: investment biobanking - increased returns from tissue samples. Nat Rev Clin Oncol 2013, 10:128-129.

3. Eccles SA, Aboagye EO, Ali S, Anderson AS, Armes J, Berditchevski F, Blaydes JP, Brennan K, Brown NJ, Bryant HE, Bundred NJ, Burchell JM, Campbell AM, Carroll JS, Clarke RB, Coles CE, Cook GJR, Cox A, Curtin NJ, Dekker LV, Dos Santos SI, Duffy SW, Easton DF, Eccles DM, Edwards DR, Edwards J, Evans DG, Fenlon DF, Flanagan JM, Foster C, et al: Critical research gaps and translational priorities for the successful prevention and treatment of breast cancer. Breast Cancer Res 2013, 15:R92.

4. Help us find the cures: an action plan to tackle critical gaps in breast cancer research. [www.breastcancercampaign.org/helpusfindthecures]

$10.1186 / \mathrm{bcr} 3566$

Cite this article as: Morgan: Help us find the cures. Breast Cancer Research 2013, 15:107 